\title{
Culture-negative endocarditis: contribution of bartonella infections
}

\author{
A S Breathnach, J M Hoare, S J Eykyn
}

\begin{abstract}
Two cases of bartonella endocarditis are described: one in a 55 year old homeless alcoholic man, caused by Bartonella quintana; the other in a 41 year old male with a history of exposure to cat fleas, caused by $B$ henselae. Serological testing and polymerase chain reaction of the excised valves were used to identify the organisms. False positive serology for chlamydia was detected in one case.
\end{abstract}

(Heart 1997;77:474-476)

Keywords: bartonella infections; culture-negative endocarditis; zoonoses

Approximately $10 \%$ of cases of endocarditis in St Thomas' Hospital are blood culture negative, two fifths of which is because of previous antibiotic therapy. Bartonella spp are increasingly recognised as a cause of endocarditis. They are fastidious organisms and cannot be isolated from blood by routine methods, and thus cause "culture negative" infections. The diagnosis can be made serologically, but speciation requires molecular biology techniques. $B$ henselae is associated with exposure to cats, and $B$ quintana with homelessness and poor hygiene.

\section{Case 1}

A 55 year old homeless alcoholic man presented with a two week history of swollen painful legs and vomiting. He claimed to have been well before this. There was no animal contact other than with dogs of his homeless companions, and no definite history of infestation.

On admission he was unkempt with poor dentition. He did not have a fever but developed a temperature of $38^{\circ} \mathrm{C}$ the following day. His fingers were clubbed, and there was oedema and erythema of both legs below the knee, with many petechiae. There was a systolic murmur, loudest at the apex, and an early diastolic murmur. Ward urine analysis revealed haematuria and proteinuria, and laboratory investigations a haemoglobin of $91 \mathrm{~g} / \mathrm{l}$, a white cell count (WCC) of $7 \cdot 1 \times 10^{9} / 1$, an erythrocyte sedimentation rate (ESR) of $71 \mathrm{~mm}$ in the first hour, and a $\mathrm{C}$ reactive protein (CRP) of $47 \mathrm{mg} / 1$. Two sets of blood cultures, taken before antibiotics, were sterile despite prolonged incubation.

The initial diagnosis was cellulitis and he was treated with intravenous amoxycillin $500 \mathrm{mg}$ three times a day. A transoesophageal echocardiogram detected vegetations on both the mitral and aortic valves, with severe mitral and moderate aortic regurgitation. The dose of amoxycillin was increased to $1 \mathrm{~g}$ four times a day, and gentamicin $80 \mathrm{mg}$ three times a day was added. He was referred for valve replacement because of progressive heart failure and this was performed 12 days after admission. At surgery, gross changes of endocarditis were noted, particularly of the mitral valve; the aortic and mitral valves were replaced with $23 \mathrm{~mm}$ and $29 \mathrm{~mm}$ prostheses (Carbomedics, West Sussex, UK). Gram stained smears of the excised valves showed no pus cells or organisms and prolonged culture (for three weeks) of the excised valves was negative.

Serum taken one week after admission was positive by complement fixation assay for chlamydia group antigen, at a titre of 1:1280. This was confirmed by immunofluorescence and very high levels of IgG antibody were detected against Chlamydia pneumoniae, $C$ psittaci, and $C$ trachomatis. As cross reactions with chlamydia occur in Bartonella spp, and because the latter are associated with homelessness and poor hygiene, bartonella serology was performed, initially in the Central Public Health Laboratory, Colindale. Serology was positive, but with a "non-specific" pattern of immunofluorescence. Serum, blood, and the excised heart valves were sent to Professeur Didier Raoult in the Unité des Rickettsies, Marseilles, France who reported high titres for IgG to Bartonella henselae (1:5120) and $B$ quintana (1:800), and a titre of $1: 25$ for $\operatorname{IgM}$ to $B$ quintana. Polymerase chain reaction (PCR) analysis of the excised valves was positive for $B$ quintana.

When the initial high chlamydia titre was reported the treatment was changed to oral rifampicin $600 \mathrm{mg}$ daily and doxycycline $200 \mathrm{mg}$ daily. The patient was discharged two weeks after valve replacement on these antibiotics, but failed to keep his outpatient appointments. He was admitted eight months later with acute alcohol withdrawal and abnormal 
clotting due to oral anticoagulants. He was otherwise well and was afebrile. $\mathrm{He}$ was unable to recall how long he had continued his antibiotics after discharge. No specific treatment was given for bartonella infection on his second admission. Repeat serum was positive for Bartonella spp by immunofluorescence, at a titre of $1: 6400$ for IgG to $B$ quintana, $1: 5120$ for IgG to $B$ henselae, and 1:25 for IgM to $B$ quintana.

\section{Case 2}

A 41 year old male nursery school teacher presented to an eye casualty department complaining of partial loss of vision in his left eye of 12 hours duration. During the previous eight weeks he had suffered increasing fatigue and shortness of breath, and had developed a rash on both legs. He also noticed that his fingernails were changing shape. The patient had a complicated and unusual medical history, with congenital polydactyly, rheumatoid arthritis, iritis, and a systolic murmur detected while undergoing surgery for a fractured ankle. At 13 years old he had dentures fitted as a result of severe dental caries. He regularly took non-steroidal analgesics for arthritis. He kept two adult cats, and had been repeatedly bitten by their fleas four weeks before his first symptoms.

On admission he had a fever $\left(38.8^{\circ} \mathrm{C}\right)$, clubbing, and petechiae on both legs. He had a left upper temporal quadrantanopia, with a branch retinal artery occlusion on fundoscopy. There was no lymphadenopathy. There were no signs of heart failure, but he had ejection systolic and early diastolic murmurs. Laboratory investigations showed a haemoglobin of $84 \mathrm{~g} / \mathrm{l}$, a WCC of $5 \cdot 1 \times 10^{9} / 1$, an ESR of $27 \mathrm{~mm}$ in the first hour, and a CRP of $52 \mathrm{mg} / 1$.

Four sets of blood cultures were taken and treatment was started with intravenous benzyl penicillin $1.2 \mathrm{~g}$ four times a day and gentamicin $80 \mathrm{mg}$ three times a day. Transoesophageal echocardiography showed large aortic vegetations and a possible aortic root abscess. Nine days after admission he was operated on, when a calcified bicuspid aortic valve was excised with an attached vegetation $20 \mathrm{~mm}$ in diameter. An abscess cavity was found extending externally behind the mitral annulus and an aortic root replacement was carried out with a size $2 \cdot 3$ homograft. Microscopy of the excised valve showed no pus cells and no organisms, and prolonged culture was negative.

The blood cultures remained negative despite prolonged incubation. Serological tests for chlamydia, coxiella, and mycoplasma were negative. Serum sent to the Unité des Rickettsies yielded high titres of IgG to $B$ quintana $(1: 3200)$ and to $B$ henselae $(1: 1600)$; tests for IgM were negative. PCR analysis of the excised vegetation was positive for $B$ henselae. Antibiotic therapy was stopped four weeks after surgery, and six weeks later the patient felt better than he had for many months. He had a normal WCC and CRP.

There is no recorded association between polydactyly and bicuspid aortic valves, but it is intended to screen the patient's daughters by echocardiography.

\section{Discussion}

Culture negative endocarditis accounts for between $5 \%$ and $14 \%$ of cases in most recent series, ${ }^{1}$ and for $10 \%$ of the 221 cases seen in St Thomas' Hospital between 1985 and 1996. The term "culture negative endocarditis" is used to mean endocarditis with negative blood cultures. It is imprecise, in that blood culture techniques may vary between laboratories, and in some patients although blood cultures are negative, culture of the excised valve may yield the causative organism, especially if antibiotics have been given.

Previous antimicrobial therapy is the most common cause of culture negative endocarditis, accounting for $67 \%$ of cases in one series, ${ }^{2}$ and $39 \%$ in St Thomas' Hospital. This suppression of bacteraemia lasts considerably longer than the persistence of detectable antibiotic in the blood, and is related to the dose and duration of antibiotic therapy. ${ }^{3}$ The suppression may be partial rather than total, and can sometimes be countered by increasing the number of blood culture samples. When previous antibiotic use is excluded, only about $5 \%$ of cases of endocarditis are genuinely culture negative. ${ }^{4}$ For routine laboratories, serology is the only means of detecting chlamydia, coxiella, and bartonella.

The Bartonella genus currently consists of 10 species, ${ }^{5}$ some of which were recently regarded as rickettsiae ${ }^{6}$; the genus is most closely related to Brucella and Agrobacterium. Bartonella are small, slowly growing Gram negative rods, and are difficult to isolate by routine laboratory methods. The reported range of human disease associated with Bartonella spp is shown in

Spectrum of human disease from Bartonella species infection

\begin{tabular}{|c|c|c|c|c|c|}
\hline & Endocarditis & $\begin{array}{l}\text { Fever, } \\
\text { bacteraemia }\end{array}$ & $\begin{array}{l}\text { Vasoproliferative } \\
\text { disorders of skin } \\
\text { and viscera }\end{array}$ & $\begin{array}{l}\text { Cat } \\
\text { scratch } \\
\text { disease }\end{array}$ & $\begin{array}{l}\text { Important factors in acquisition; } \\
\text { other points of note }\end{array}$ \\
\hline B quintana ${ }^{7-11}$ & + & $+*$ & Bacillary angiomatosis & $\begin{array}{l}\text { Single possible } \\
\text { case reported }\end{array}$ & $\begin{array}{l}\text { Louse-borne; homeless, poor hygiene; } \\
\text { A rare cause of bacillary angiomatosis }\end{array}$ \\
\hline$B$ henselae $e^{101213}$ & + & + & $\begin{array}{l}\text { Bacillary angiomatosis, } \\
\text { Bacillary peliosis hepatis } \\
\text { Neuropsychiatric disease }\end{array}$ & + & Cat contact; AIDS \\
\hline$B$ bacilliformis ${ }^{14}$ & & $+\star \star$ & Verruga peruana & & $\begin{array}{l}\text { Spread by Peruvian sandfly; } \\
\text { confined to Northern Andes }\end{array}$ \\
\hline$B$ elizabethae ${ }^{15}$ & + & + & & & Single case report only \\
\hline
\end{tabular}

+ Cases reported; ${ }^{\star}$ Trench fever; ${ }^{\star}$ Oroya fever. 
the table; only four species have so far been implicated.

Bartonella (formerly Rochalimaea) quintana causes trench fever, ${ }^{8}$ and has recently been reported as a cause of native valve endocarditis in homeless and alcoholic patients, ${ }^{7}$ frequently in the absence of any underlying valve lesion. ${ }^{16}$ Trench fever is spread by the human body louse, which is the presumed vector of $B$ quintana infections in homeless men, ${ }^{9}$ although proof of infestation in our first patient was lacking. Endocarditis has also been reported with $B$ henselae, and in many cases cat contact has been noted. ${ }^{12} B$ henselae has been detected in the blood of domestic cats and in their fleas, by culture and PCR analysis. ${ }^{1718}$ There is a single reported case of endocarditis due to $B$ elisabethae; whose natural reservoir is unknown. ${ }^{15}$

False positive serology for chlamydia has been described with bartonella infections, ${ }^{7}$ and it was this and the case history that led to the investigation for bartonella in the first patient. Chlamydia spp, particularly $C$ psittaci, cause endocarditis which is, by conventional means, "culture negative". Some patients with positive chlamydia serology have a definite history of bird exposure, and the homeless in London must be exposed to pigeons, but it is possible that some cases of infective endocarditis attributed to chlamydia on the basis of serology may have been caused by bartonella. Although it is possible to grow bartonella from blood cultures, ${ }^{19}$ this is difficult, and acridine orange staining of samples is required after culture, followed by subculture and incubation for several weeks; such techniques are impracticable in a routine laboratory. Serology is a reliable way to make the diagnosis, and bartonella antibodies should be sought routinely in any case of culture negative endocarditis, particularly if the patient is homeless, of poor hygiene, or a cat owner.

If a valve is excised, PCR analysis in a specialist laboratory will allow detection and speciation of bacterial DNA. The value of PCR analysis of blood samples is less clear, and is still under evaluation.

Bartonella spp are susceptible to a wide range of antibiotics in vitro, ${ }^{60}$ but experience of treatment is limited. A combination of rifampicin and gentamicin has been suggested on the basis of in vitro sensitivities (D Raoult 1995, personal communication). Neither of our cases was given this definitive treatment; although each had received gentamicin, this was only given in a low dose for its synergistic effect with penicillin. Both patients had a good outcome, and valve excision alone may be curative.

We thank Professor Didier Raoult of the Unite des Rickettsies and Dr TG Harrison of the Central Public Health Laboratory for their assistance and advice, and the clinicians for permission to report details of their patients.

1 Hoen B, Selton-Suty C, Lacassin F, Etienne J, Briançon S, Leport $\mathrm{C}$, et al. Infective endocarditis in patients with negative blood cultures: an analysis of 88 cases from a oneyear nationwide survey in France. Clin Infect Dis 1995; 20:501-6.

2 Pesanti EL, Smith IM. Infective endocarditis with negative blood cultures: an analysis of 52 cultures. $A m \mathcal{F} \mathrm{Med}$ 1979;66:43-50.

3 Pazin GJ, Saul S, Thompson ME. Blood culture positivity: suppression by outpatient antibiotic therapy in patients with bacterial endocarditis. Arch Intern Med 1982;142: 263-8

4 Tunkel AR, Kaye D. Endocarditis with negative blood cultures. N Engl F Med 1992;326:1215-7.

5 Maurin M, Raoult D. Bartonella (Rochalimaea) quintana infections. Clin Microbiol Rev 1996;9:273-92.

6 Myers WF, Grossman DM, Wisseman CL. Antibiotic susceptibility patterns in Rochalimaea quintana, the agent of ceptibility patterns in Rochalimaea quintana, the agent of
trench fever. Antimicrob Agents Chemother 1984;25:690-3.

7 Drancourt M, Mainardi J, Brouqui P, Vandenesch F, Carta A, Lehnert F, et al. Bartonella (Rochalimaea) quintana A, Lehnert F, et al. Bartonella (Rochalimaea) quintana endocarditis

8 Swift HF. Trench fever. Arch Intern Med 1920;26:76-98.

9 Spach DH, Kanter AS, Dougherty MJ, Larson AM, Coyle $\mathrm{MB}$, Brenner DJ, et al. Bartonella (Rochalimaea) quintana bacteremia in inner-city patients with chronic alcoholism. N Engl f Med 1995;442:424-8.

10 Maurin M, Roux V, Stein A, Ferrier F, Viraben R, Raoult D. Isolation and characterisation by immunofluorescence, sodium dodecyl sulfate-polyacrylamide gel electrophoresis, Western blot, restriction fragment length polymorphismPCR, 16S RNA gene sequencing, and pulsed-field gel electrophoresis of Rochalimea quintana from a patien with bacillary angiomatosis. F Clin Microbiol 1994;32: 1166-71.

11 Raoult D, Drancourt M, Carta A, Gastault JA. Bartonella (Rochalimaea) quintana isolation in a patient with chronic adenopathy, lymphopenia and a cat [letter]. Lancet 1994; 343:977.

12 Holmes AH, Greenough TC, Balady GJ, Regnery RL, Anderson BE, O'Keane JC, et al. Bartonella henselae endocarditis in an immunocompetent adult. Clin Infect Dis 1995;21:1004-7.

13 Schwartzman WA, Patnaik M, Angulo F, Visscher BR Miller EN, Peter JB. Bartonella (Rochalimaea) antibodies, Miller EN, Peter JB. Bartonella (Rochalimaea) antibodies, dementia and cat ownership among men infected with human

14 Roberts NJ. Bartonella bacilliformis (Bartonellosis). In: Mandell GL, Douglas RG, Bennet JE, eds. Principles and practice of infectious diseases, 4th ed. New York: Churchil Livingstone, 1995:1870-2.

15 Daly JS, Worthington MG, Brenner DJ, Moss CW, Hollis DG, Weyant RS, et al. Rochalimaea elizabethae sp. nov. isolated from a patient with endocarditis. $\mathcal{f}$ Clin Microbiol 1993;31:872-81.

16 Raoult D, Fournier PE, Drancourt M, Marrie TJ, Etienne J, Cosserat J, et al. Diagnosis of 22 new cases of Bartonella endocarditis. Ann Intern Med 1996;125:646-52.

17 Regnery R, Martin M, Olson J. Naturally occurring "Rochalimaea henselae" infection in domestic cat. Lancet 1992;340:557-8.

18 Koehler JE, Glaser CA, Tappero WJ. Rochalimaea henselae infection. A new zoonosis with the domestic cat as reservoir. $\mathcal{F A M A}$ 1994;271:531-5.

19 Larson AM, Dougherty MJ, Nowoiejski DJ, Welch DF, Matar GM, Swaminathan B, Coyle MB. Detection of Bartonella (Rochalimaea) quintana by routine acridine orange staining of broth blood cultures. $\mathcal{f}$ Clin Microbiol orange staining of

20 Maurin M, Raoult D. Antimicrobial susceptibility of Rochalimaea quintana, Rochalimaea vinsonii, and the newly recognised Rochalimaea henselae. If Antimicrob Chemother 1993;32:587-94. 